\title{
Sensitivity of the snow energy balance to climatic changes: prediction of snowpack in the Pyrenees in the 21st century
}

\author{
J. I. López-Moreno ${ }^{1,2, *}$, S. Goyette ${ }^{2}$, M. Beniston ${ }^{2}$, B. Alvera ${ }^{1}$ \\ ${ }^{1}$ Instituto Pirenaico de Ecología, CSIC, Campus de Aula Dei, PO Box 202 Zaragoza 50080, Spain \\ ${ }^{2}$ Climatic Change and Climate Impacts Group, University of Geneva, Batelle/D7, Chemin de Drize, 1227 Carouge (Geneve), \\ Switzerland
}

\begin{abstract}
The present paper analyses and quantifies the sensitivity of snowpack to climate change, and assesses implications for snow processes in the central Pyrenees under the climatic conditions projected by a set of 9 regional climate models (RCMs) for the end of the 21st century, under the IPCC emission scenario SRES A2. The methodology was based on comparison of the snow series obtained by simulating the energy balance of a snow surface driven by climatic conditions recorded during the period from 1996 to 2006, with snow series obtained by simulations for the same period that included various changes in magnitude for each of the climatic drivers (sensitivity analysis); and the changes projected by the RCMs to the end of the 21st century. Results showed a marked sensitivity of snowpack duration and thickness to shifts in temperature, precipitation and solar radiation. RCMs suggest that the most significant changes expected in the study area are related to temperature, which is the main parameter responsible for the predicted changes in future snow processes. A large coherence was found among the simulations made using the projections of the 9 regional climate models. Comparison with respect to current conditions indicated a decrease of 50 to $60 \%$ in maximum snow water equivalent, the occurrence at least 1 mo earlier of the maximum snow water equivalent, and a reduction in the duration of the snowpack by around 2 mo. In addition, the 3 snow parameters will be subject to a marked increase in inter-annual variability compared to the observed conditions.
\end{abstract}

KEY WORDS: Snow - Snow energy balance $\cdot$ SEB $\cdot$ Climate change $\cdot$ Regional climate models RCMs $\cdot$ Pyrenees

Resale or republication not permitted without written consent of the publisher

\section{INTRODUCTION}

The presence of a seasonal snow cover is one of the main features of both mild and cold mountain regions. The depth and duration of the snowpack control a large number of hydrological and geomorphological processes, as well as the phenology of plants and animals (López-Moreno \& García-Ruiz 2004, Mellander et al. 2005). Many reports support the high dependence of snowpack evolution on climatic conditions (e.g. Beniston 1997, López-Moreno \& Vicente-Serrano 2007), and significant effort has gone into assessing and quantifying the effects of projected climate change over the next decades on snow accumulation and melting processes for mountain regions over the world (Rasmus et al. 2004, Dankers \& Christensen 2005, Keller et al. 2005, Merritt et al. 2006, Hantel \& HirtlWielke 2007, Mellander et al. 2007). A recent publication (López-Moreno et al. 2008) has highlighted the important shifts in precipitation and temperature that will occur in the Pyrenees in the next decades. However, the impacts on snowpack remain insufficiently studied despite the potential consequences of such changes.

The topography and climate of the Pyrenees allows the development of an extensive and thick snow cover 
from December to April in areas $>1500 \mathrm{~m}$ above mean sea level (a.s.l.), with a longer duration of snow cover at higher altitudes and in shaded areas (García-Ruiz et al. 1986, López-Moreno \& Nogués-Bravo 2005). In this region, snow controls many ecological processes and also has important socio-economic implications, mainly due to (1) the large contribution of snow melt to the amount and seasonal distribution of runoff in Pyrenean river basins, which plays a major role in water management in the semiarid and highly populated Ebro valley (López-Moreno \& García-Ruiz 2004) and (2) the significant development of winter tourism in recent decades, which represents one of the main sources of revenue for the region. Thus, this area could be particularly sensitive to the impact of expected climatic change in the 21st century (López-Moreno et al. 2008).

Within this context, the aim of the present study was to assess the impact of predicted climate change on snow processes in the Pyrenees. For this purpose, the snow energy balance (SEB) in the area was simulated for climatic conditions in the recent past (1996 to 2006) and for future conditions driven by projections of 9 different regional climate models (RCMs) for the end of the 21st century. The use of a multi-model approach enabled an assessment of the coherence amongst the projections of the different RCMs, and the development of a robust expected mean change with different confidence intervals (Räisänen 2007).

The lack of long-term detailed meteorological records in the region obligated the analysis to be carried out using the single location where point measurements have been made for longer than a decade (the Izas Experimental Station). Uncertainties resulting from the SEB model used and the RCM projections, as well as the applicability of results from an individual location to the whole region, are discussed.

\section{STUDY AREA}

The Pyrenees are a mountain range located in the north-eastern part of the Iberian Peninsula, between France and Spain. The range is bounded by the Atlantic Ocean to the west and the Mediterranean Sea to the east (Fig. 1). Altitudes vary from about 500 to $3500 \mathrm{~m}$ a.s.l., with a contrasted relief. There is a marked transition in precipitation and temperature conditions from the Atlantic to the Mediterranean, as well as significant changes in macrorelief. Annual precipitation falls predominantly during winter in areas adjacent to the Atlantic, and during spring and autumn in the Mediterranean regions.

The study area (Izas Experimental Station; $42^{\circ} 44^{\prime} \mathrm{N}$, $0^{\circ} 25^{\prime} \mathrm{W}$ ) is located at $2056 \mathrm{~m}$ a.s.l. and is very close to the main divide of the Pyrenees in the headwaters of the Gallego River in Spain. As it is in a transition zone between the Atlantic and the Mediterranean, it has mixed climatic influences and conditions. The mean annual temperature is $3^{\circ} \mathrm{C}$, and there are $130 \mathrm{~d} \mathrm{yr}^{-1}$ on which the mean temperature is $<0^{\circ} \mathrm{C}$. Mean annual precipitation is around $2000 \mathrm{~mm}$, of which more than half falls as snow (Del Barrio et al. 1997, Anderton et al. 2004). Despite having a mean winter temperature $<0^{\circ} \mathrm{C}$, the area is subject to intense winter warm spells, which trigger melting events and major metamorphosis of the snowpack throughout the whole snow season.

\section{DATA AND METHODS}

\subsection{The surface energy balance model GRENBLS}

A number of different numerical modelling approaches have been taken into account to simulate snow cover, ranging from simplified degree-day melt
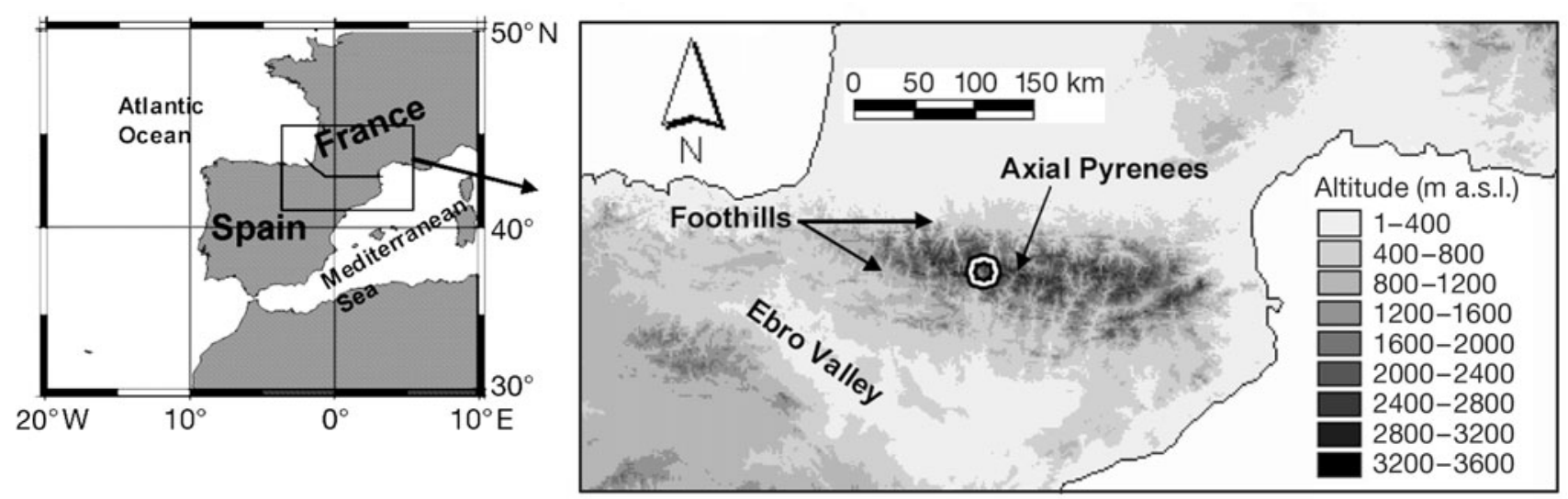

Fig. 1. Location of the Pyrenees (left) and the study site (right). @Izas Experimental Station 
models (e.g. Anderson 1973), to single- (e.g. Outcalt et al. 1975) and multi-layer (e.g. Anderson 1976, Brun et al. 1989) energy balance models. Snow model evaluations during the Snow Model Intercomparison Project (SnowMIP) revealed that single layer models were able to provide realistic representations of snow cover accumulation, melt and physical properties over a range of snow cover climates (Etchevers et al. 2004). The SnowMIP gathered several types of models and parameterizations, ranging from simplified schemes such as those used in the global climate model (GCM), snow melt models used in hydrology and detailed multi-layer snow models used for avalanche forecasts or research in snow physics. Single layer energy balance models (also referred to as surface energy balance models or SEBM) have been shown to reproduce the snow water equivalent (SWE) quite realistically with respect to more complex multi-layer models (e.g. Brown et al. 2006).

In the present study, a single snow-layer SEBM called GRENBLS (GRound ENergy BaLance for natural Surfaces), driven by a time series of observed atmospheric data, has proven genuine skill in reproducing many aspects of the evolution of alpine snowpacks (Keller \& Goyette 2005, Keller et al. 2005). GRENBLS is a physically based model driven by hourly input data of screen air-temperature, $T_{\text {air }}(\mathrm{K})$; dew point temperature, $T_{\mathrm{d}}(\mathrm{K})$; anemometer-level wind magnitude, $W_{\mathrm{s}}$ $\left(\mathrm{m} \mathrm{s}^{-1}\right)$; precipitation, $P\left(\mathrm{~mm} \mathrm{~s}^{-1}\right)$; surface pressure, $p_{\mathrm{sfc}}$ (hPa); and incident solar radiation $(K \downarrow)$. This model has an explicit underlying multi-layer soil of $1 \mathrm{~m}$ depth of 'medium-coarse texture' covered at $70 \%$ with low vegetation (snow mask of $3 \mathrm{~cm}$ ), and a distinct snow layer. It computes the radiative fluxes (incoming solar radiation may also be prescribed), the surface turbulent sensible and latent fluxes where the bulk heat and moisture transfer coefficients are parameterised according to the ideas of Benoît (1977) on the basis of the MoninObukov similarity theory, as well as the heat flux in the ground and in the snowpack. Surface temperature, soil wetness and snow mass are prognostic variables, the latter in terms of SWE. Energy budget also considers the energy change associated with the melting of frozen soil moisture and snow. The temperature of the snowpack is computed prognostically through the heat storage using a force-restore method (e.g. Stull 1988, Chapter 7, McFarlane et al. 1992). As shown in detail in Keller \& Goyette (2005), the model also computes the surface water budget in terms of surface moisture (liquid and frozen) and snow separately, liquid and solid precipitation rates, the melting rate of snow and frozen soil, the surface evapotranspiration, the snow sublimation, and the total runoff partitioned into surface saturation and bottom drainage. Precipitation is considered as solid if $T_{\text {air }}$ is less than the triple point of water. Liquid precipitation on a snowpack induces snowmelt. Melted water goes directly into the soil as liquid moisture. Snow is modelled as an evolving 1-layer pack characterised by a temperature, $T_{\text {snow }}(\mathrm{K})$; a mass, $M_{\text {snow }}\left(\mathrm{kg} \mathrm{m}^{-2}\right)$; and a density, $\rho_{\text {snow }}\left(\mathrm{kg} \mathrm{m}^{-3}\right)$. The surface energy budget is computed at each model timestep over snow cover. The radiative and turbulent fluxes are first computed. Then, the heat storage in the snowpack is computed and, if it is positive and the snow temperature is below the melting point, the excess energy is first used to raise the temperature of the pack. Once its temperature reaches the melting point, any additional excess energy is used to melt the snow. The temperature of the snow is held below the melting point until the snow has melted. The melted snow goes directly into the ground as liquid moisture. The evolution in snow density from metamorphosis and settling is assumed to follow an exponential time decay expression using a maximum mean density of a non-melting snowpack of $300 \mathrm{~kg} \mathrm{~m}^{-3}$. New falling snow has a fixed density of $100 \mathrm{~kg} \mathrm{~m}^{-3}$. In a similar manner, snow albedo changes accompanying snow aging are parameterized as a time-decay function from an initial fresh snow albedo of 0.80. GRENBLS also incorporates total cloudiness, hereafter referred to as ' $C$ ' as an input parameter. Clouds influence the intensity of the downward solar and infrared radiation at the surface. At terrestrial temperatures, about $70 \%$ of the energy in the black body spectrum lies outside the waveband of the atmospheric window (8 to $14 \mu \mathrm{m}$ ), whereas the wavebands lying within the atmospheric window neither absorb nor radiate. At all other wavelengths, the atmosphere is considered to behave as a black body. Hence, $70 \%$ of the outgoing longwave radiation is absorbed by and re-radiated downwards at wavelengths outside of the window; that is, the atmospheric emissivity $\varepsilon_{\mathrm{a}}=L_{\mathrm{o}} \downarrow / \sigma T_{\text {air }}^{4}$ is 0.7 , where $L_{\mathrm{o}} \downarrow$ is the cloudless sky flux density and $\sigma$ the Stefan-Boltzmann constant. This is assumed to be independent of temperature. Paltridge \& Platt (1976) state that the downward energy flux density $(1-0.7) \varepsilon_{\mathrm{c}} \sigma T_{\mathrm{c}}^{4}$ having a mean value of $60 \mathrm{~W} \mathrm{~m}^{-2}$ may be used generally where $\varepsilon_{\mathrm{c}}$ and $T_{\mathrm{c}}$ are the clouds' emissivity and temperature. Clouds affect the flux density at the ground by contributing longwave radiation within the window such that:

$$
L \downarrow=L_{\mathrm{o}}{ }^{\downarrow}+(1-0.7) \varepsilon_{\mathrm{C}} \sigma T_{\mathrm{C}}^{4} C
$$

where $C \leq 1$.

\subsection{Data}

Most of the important climatic drivers of GRENBLS have been recorded on an hourly basis since 1996 at the Izas Station. This represents the longest and most complete meteorological record for simulating SEB on 
the southern slopes of the Pyrenees. Despite the fact that the data cover only a decade, the years included in the series exhibit noticeably contrasting conditions in climate and snow processes; which is the most important requirement to assess the impact of climate change on snowpack once the series are modified according to RCM projections. The data that have been recorded are air temperature $\left(T_{\text {air }}\right)$, precipitation $(P)$, relative humidity $\left(R_{\mathrm{h}}\right)$, dew point temperature $\left(T_{\mathrm{d}}\right)$, wind speed $\left(W_{\mathrm{s}}\right)$, incoming and reflected radiation, and snow depth. Atmospheric pressure $\left(p_{\text {sfc }}\right)$ was estimated from observed values ( $\left.p_{\text {obs }}\right)$ at a nearby station $(850 \mathrm{~m}$ a.s.l.) accounting for the lower altitude of this station by applying the barometric correction:

$$
p_{\text {sfc }}=p_{\text {obs }}\left(\frac{T_{\text {air }}}{T_{\text {air }}+\gamma \Delta z}\right)^{\frac{g}{R_{\mathrm{d}} \gamma}}
$$

where, $T_{\text {air }}$ is the observed temperature (in Kelvin), $\Delta z$ is the altitude difference, $\gamma$ is a mean vertical lapse rate defined as $-6.5 \mathrm{~K} \mathrm{~km}^{-1}, g$ is the gravitational acceleration $\left(9.81 \mathrm{~m} \mathrm{~s}^{-1}\right)$, and $R_{\mathrm{d}}$ is the specific gas constant for dry air $\left(287.04 \mathrm{~J} \mathrm{~kg}^{-1} \mathrm{~K}^{-1}\right)$.

Sensors are of known brands (Vaisala HMP 35 A for $T_{\text {air }}$ and $R_{\mathrm{h}}$ Qualimetrics $6011 \mathrm{~B}$ tipping bucket rain gauge; anemometer Young 03002; pyranometer Swissteco for $K \downarrow$ and $K \uparrow$ solar radiation; Campbell SR50 ultrasonic sensor for snow depth). In some cases they are duplicated ( $\left.T_{\text {air }}, R_{\mathrm{h}}, W_{\mathrm{s}}, K \downarrow\right)$ ), and the values of both sensors are continuously compared; they are also checked on the spot with portable sensors during data collection visits ( $T_{\text {air }}$ and $R_{\mathrm{h}}$ snow depth). Some data (e.g. precipitation, snow depth) are compared with those of nearby meteorological stations. Snow depth is measured every 5 min with a Campbell SR50 ultrasonic sensor, which ensures $\pm 1 \mathrm{~cm}$ of accuracy. The larger uncertainty in data comes from measurement of solid precipitation; this is derived from measured changes in snow depth (assuming an initial density of $100 \mathrm{~kg} \mathrm{~m}^{-3}$ ) and validated with water recorded in a accumulative rain gauge and density data from a $1.5 \times$ $1.5 \mathrm{~m}$ snow pillow installed $3 \mathrm{yr}$ ago.

Multi-layer clouds have been computed diagnostically using NCEP-NCAR (Kalnay et al. 1996) 6 h temperature and specific humidity on a number of pressure levels over the region and period under study. First, the relative humidity is computed as a function of the temperature and the specific humidity at pressure level $p$. Then, the cloud fraction, $\mathrm{Cl}_{p}$, is computed according to a cloud onset function producing the following fraction of clouds (Laprise et al. 1998):

$$
\mathrm{Cl}_{p}=\frac{\mathrm{R}_{\mathrm{h}, p}-H_{\mathrm{o}, p}}{1-H_{\mathrm{o}, p}}
$$

where $\mathrm{R}_{\mathrm{h}, p}$ represents the relative humidity at pressure level $p$, and $H_{o, p}$ is the moisture threshold at the same level computed on the basis of the fractional probability of water phase in the clouds as a function of temperature according to the ideas of Rockel et al. (1991). Cloud amounts diagnosed at 7 pressure levels (namely $300,400,500,600,700,850$ and $925 \mathrm{hPa}$ ) and fog (estimated at $1000 \mathrm{hPa}$ ) are interpolated and used as hourly input in the model. GRENBLS has an option of using cloud amount $C_{i}, i=1,8$. The total cloud amount, $C_{\text {, }}$ therefore, cannot exceed 1 (or 8/8). In the pre-processing phase of the cloud computations using atmospheric relative humidity, we have shifted the clouds cast on pressure levels upward, i.e. treated pressure level clouds as sigma level clouds. The effect of clouds is to scale linearly the background value of downward infrared radiation with a value of 0 during clear sky to $60 \mathrm{~W} \mathrm{~m}^{-2}$ for an overcast sky.

\subsection{Climatic change scenarios and modification of observation series}

Information on predicted climate change was obtained from the outputs of simulations of the different drivers of snowpack ( $T_{\text {air }}, P, T_{\mathrm{d}}, p_{\mathrm{sfc}}, W_{\mathrm{s}}$ and $\left.K \downarrow\right)$ for 9 RCMs developed by different institutions collaborating in the EU-funded PRUDENCE project. Models used included HIRHAM: the Danish Meteorological Institute (DMI), HIRHAM: the Norwegian Meteorological Institute (METNO), HADRM3: the Hadley Center (HC), RCAO: the Swedish Meteorological and Hydrological Institute (SMHI), PROMES: Universidad Complutense de Madrid (UCM), REGCM: the Abdus Salam International Centre for Theoretical Physics of Weather and Climate Section (ICTP), CHRM: the Swiss Federal Institute of Technology (ETH), RACMO: the Royal Netherlands Meteorological Institute (KNMI) and REMO: the Max Plank Institute for Meteorology (MPI). All were driven by the GCM HadAM3H for the European continent. The models were previously run for a control period (1961 to 1990) and under different future greenhouse emission scenarios defined by the Intergovernmental Panel for Climate Change (IPCC; Nakicenovic et al. 1998). In the present study, climate change assumed a SRES A2 scenario, which predicts strong increases of atmospheric greenhouse gases (GHG) in coming decades and has been commonly used in climate change studies (Christansen \& Christansen 2003, 2004, Beniston 2006, Beniston et al. 2007, Mellander et al. 2007, Thodsen 2007). RCM outputs were made available on a daily basis at a spatial resolution of roughly $50 \mathrm{~km}\left(0.44\right.$ to $\left.0.5^{\circ}\right)$. The series for the grid cell whose centre in each model was closest to the study site was used for climate change calculations (as done by Rasmus et al. 2004, Keller et al. 2005). 
With regard to the accuracy of RCMs to reproduce climatic conditions during a control period in the Pyrenees, López-Moreno et al. (2008) concluded that high reliability of the RCMs occurred in reproducing observed temperature, with biases around $1^{\circ} \mathrm{C}$. Biases in simulated precipitation compared to observed precipitation were within 10 to $20 \%$. These values are in line with the errors found for Europe in previous quality assessments of RCMs over Europe (Giorgi et al. 2004, Dequé et al. 2005). An adequate analysis of accuracy of the other outputs provided by $\mathrm{RCMs}\left(W_{\mathrm{s}}, R_{\mathrm{h}}\right.$, $p_{\text {sfc }}$ and solar radiation) is a difficult task, as the numbers of available records are usually low, and their lengths are shorter than control simulations of RCMs; this explains the lack of studies in the available literature devoted to analyse the accuracy of these parameters. However, PRUDENCE model simulation outputs are used to compute changes, or, in other words, 'deltas' $(\Delta$, differences between control and scenario runs); this fact reduces the degree of potential uncertainty related to the quality of RCM outputs, as 'deltas' are less sensitive to model errors and can thus be used to perturb the observations in an adequate manner to produce consistent future climate change conditions (López-Moreno et al. 2008).

In order to provide GRENBLS with driving variables representative of future climate conditions, RCM outputs were considered for both 1961 to 1990 and 2071 to 2100 periods. The magnitude of climate change was determined by subtracting the variables of the control runs (1961 to 1990) from the predicted future climate (2070 to 2100). We assumed that climate change will not be constant throughout the year, and will not equally affect all parts of the distribution of the series. Consequently, we calculated the magnitude of change on a monthly basis and for each decile of the series (each part represents one-tenth of the sample). The differences were subsequently added to the $10 \mathrm{yr}$ series recorded at the Izas Station to introduce day-today and inter-annual variability into the climate scenarios (largely following Mellander et al. 2007). Modification of the observed hourly series based on daily data provided by the RCMs required a number of assumptions. (1) The hourly temperature series was created from the daily change in maximum (Tmax) and minimum (Tmin) values (which varied with the month and the decile within the observed series). Both values were allocated to the hours when they occur on average (beginning of the afternoon and sunrise for Tmax and Tmin, respectively), and, for the intervening period, a linear change between consecutive values was assumed. (2) The daily changes in the other variables were applied equally to each hour of the day. In the case of precipitation the change was only applied to the hours where precipitation occurred in the obser- vational record; thus, stationary behaviour in the number of wet days was assumed. Not all RCMs provide information on mean daily wind speed. In such cases, the mean inter-model change from the available RCMs was used in the simulations. When temperature is perturbed, $T_{\mathrm{d}}$ is recalculated assuming that the total content of humidity and specific humidity in the atmosphere remain stationary, but saturated vapour pressure changes.

Snowpack simulations were carried out in 3 ways: (1) by introducing observed climatic parameters; the resulting snow series were used to validate the model by comparing it with the snow depth measured at the observatory, and used as a reference for comparison with snow series obtained using modified climatic parameters and (2) by introducing all of the observed series of climatic drivers but one, which was varied. This procedure enabled assessment of the sensitivity of snowpack to changes in $T_{\text {air }}, P, K \downarrow, T_{\mathrm{d}}$ and $W_{\mathrm{s}}$. (3) Climatic drivers modified according to the projected climate change were introduced. Simulations were carried out assuming a change in temperature only, a change in temperature and precipitation, and a change in all the climatic drivers $\left(T_{\text {air }}, P, K \downarrow, T_{\mathrm{d}}\right.$ and $\left.W_{\mathrm{s}}\right)$. Comparison of simulated snowpack with that from observations enabled realistic changes in different snow processes to be estimated, and assessment to be made of the differential importance of each climatic driver in the future evolution of snowpack under a greenhouse climate.

Particular attention was devoted to the effects of potential changes in 3 parameters of the annual snow pattern: (1) the maximum snow water equivalent (MSWE, in $\mathrm{mm}$ ), which is a measure of the amount of water available during the melt period; (2) the date of MSWE (DMSWE; day of the hydrologic year, Day 1 = Sept 1) occurrence, which suggests the beginning of the dominance of the thawing events with respect to the accumulation events; and (3) the duration of snowpack (DSP), which encompasses accumulation and melting processes and is critical to many geomorphological and ecological processes.

\section{RESULTS}

\subsection{RCM-projected changes in climatic drivers of snow energy balance}

Fig. 2 shows monthly (December to April) projected changes in temperature $\left({ }^{\circ} \mathrm{C}\right)$ and precipitation (\%) for the different deciles to the end of the 21st century. Table 1 shows the monthly mean changes (inter-model and inter-decile averages) projected by RCMs for all the climatic drivers of the SEB. 

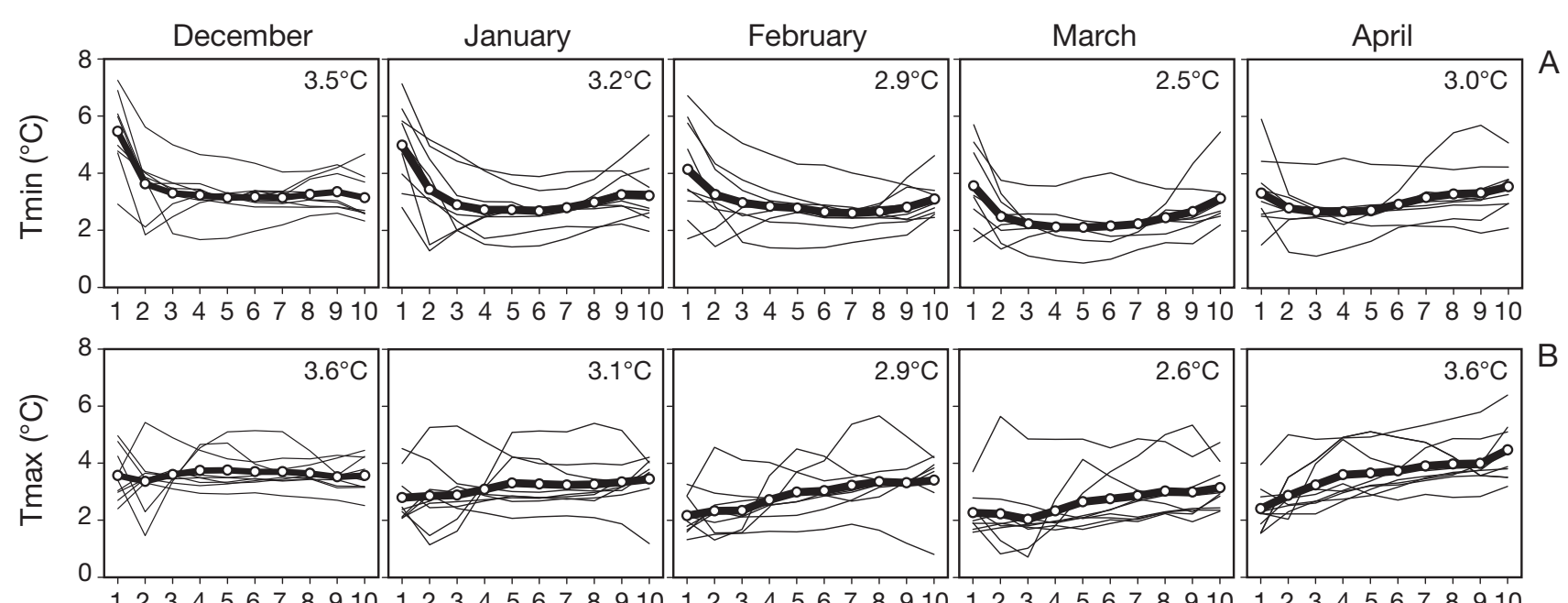

123456789101234567891012345567891012345667891012345678910
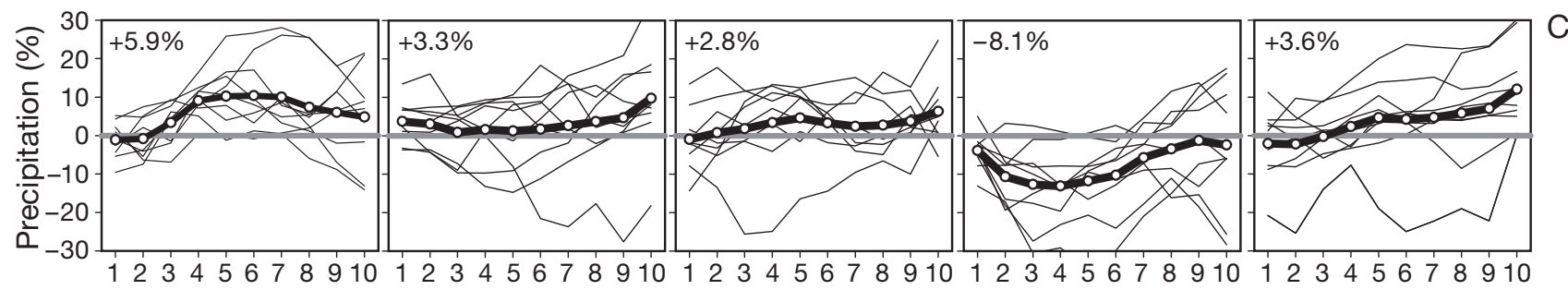

Deciles

Individual RCM models $\leadsto$ Average of the 9 models

Fig. 2. (A,B) Predicted monthly changes in temperature (A: minimum; B: maximum) and (C) precipitation for the different deciles to the end of the 21st century. The thin lines represent the projection of each regional climate model (RCM). The thick line is the inter-model average; the values given in the panels are the monthly mean of the inter-model average

Temperature (both Tmax and Tmin) is expected to increase between 2.5 and $3.9^{\circ} \mathrm{C}$ during the snow season. A tendency for more intense warming at the extremes of the distributions was also found, with greater increases in the lowest Tmin and the highest Tmax (see Fig. 2).

Precipitation tends to remain stable, with minor increases during the snow season. Decreases in precipitation are expected in March $(-8.1 \%)$ and May $(-15.2 \%$; Table 1$)$, although the influence of the latter on snow processes is negligible. Fig. 2 also indicates a lower agreement among RCMs for precipitation than for temperature, which, in some cases, may lead to differences in the sign of the expected changes. This highlights the uncertainty associated with predicting change in precipitation, and with the applicability of this parameter in simulations of snow processes in a future climate.

For other climatic drivers (Table 1), an increase in air humidity is indicated (see specific humidity $Q$ and $T_{\mathrm{d}}$ ), while $p_{\text {sfcr }} W_{\mathrm{s}}$ and $K \downarrow$ remain relatively stable over the next few decades.

Table 1. Monthly mean changes (inter-model and inter-decile averages) projected for the climatic drivers of snow energy balance by (SEB) regional climate models (REMs). $P$ : precipitation; $p_{\text {sfc }}$ : atmospheric pressure; $Q$ : specific humidity; $T_{\mathrm{d}}:$ dew point temperature; $K \downarrow$ : incoming solar radiation; $W_{\mathrm{s}}$ : wind speed

\begin{tabular}{|c|c|c|c|c|c|c|c|c|}
\hline & $\underset{\left({ }^{\circ} \mathrm{C}\right)}{\operatorname{Tmin}}$ & $\begin{array}{c}\operatorname{Tmax} \\
\left({ }^{\circ} \mathrm{C}\right)\end{array}$ & $\begin{array}{c}P \\
(\%)\end{array}$ & $\begin{array}{l}p_{\text {sfc }} \\
(\%)\end{array}$ & $\begin{array}{c}Q \\
(\%)\end{array}$ & $\begin{array}{c}T_{\mathrm{d}} \\
\left({ }^{\circ} \mathrm{C}\right)\end{array}$ & $\begin{array}{c}K \downarrow \\
(\%)\end{array}$ & $\begin{array}{c}W_{\mathrm{s}} \\
(\%)\end{array}$ \\
\hline Nov & 3.5 & 3.9 & -0.9 & -0.7 & 11.2 & 2.6 & -0.7 & -4.9 \\
\hline Dec & 3.5 & 3.6 & 5.9 & -0.8 & 18.6 & 3.8 & -3.7 & -3.7 \\
\hline Jan & 3.2 & 3.1 & 3.3 & -0.3 & 16.4 & 0.9 & -6.2 & -1.7 \\
\hline Feb & 2.9 & 2.9 & 2.8 & 0.3 & 14.7 & 2.0 & -5.2 & -1.4 \\
\hline Mar & 2.5 & 2.6 & -8.1 & 0.1 & 13.2 & 2.9 & 5.1 & 0.0 \\
\hline Apr & 3 & 3.6 & 3.6 & 0.4 & 15.2 & 3.4 & 1.8 & -0.4 \\
\hline May & 3.5 & 3.9 & -15.2 & -1.7 & 9.6 & 2.3 & 2.1 & 5.3 \\
\hline
\end{tabular}



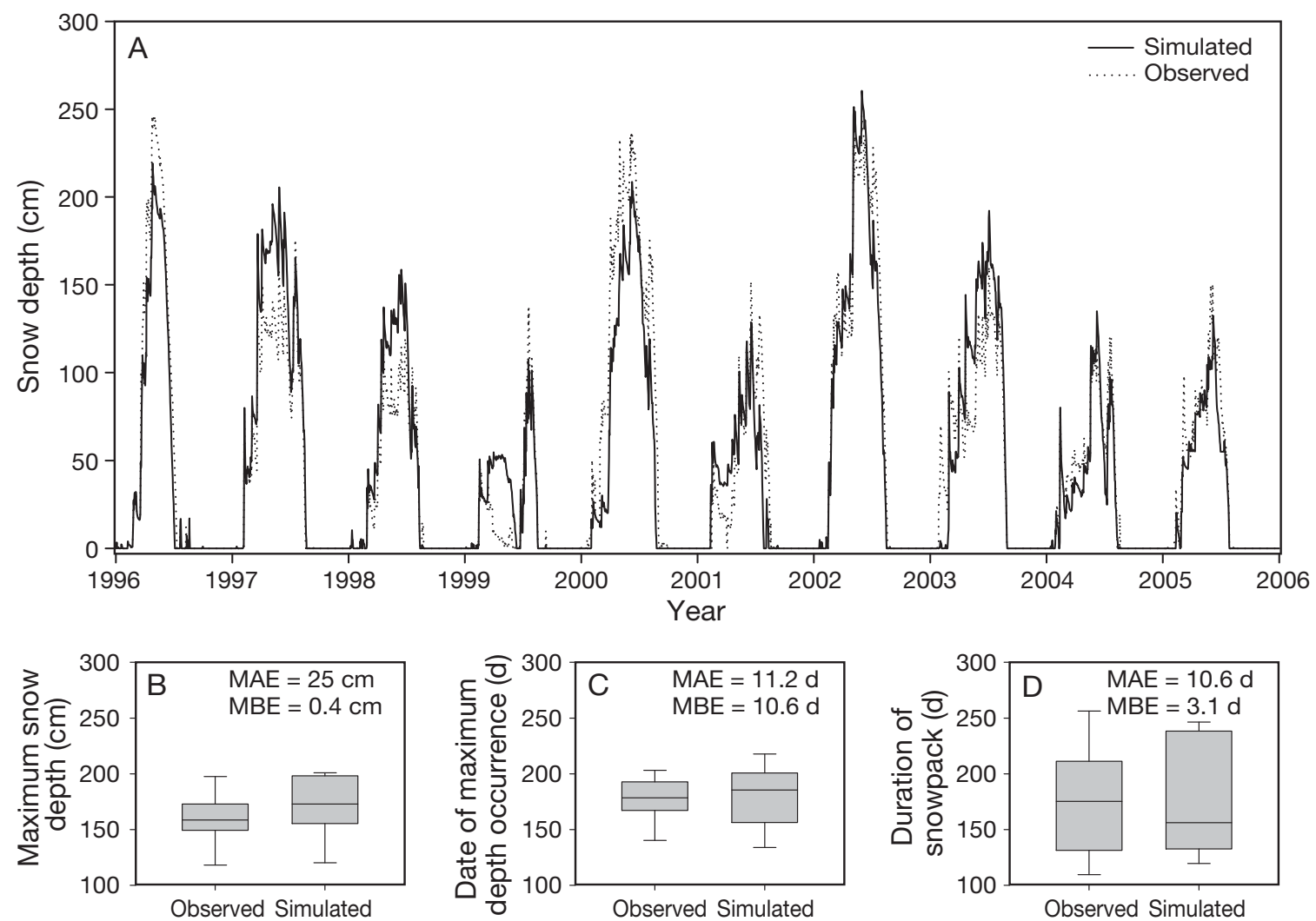

Fig. 3. Comparison of observed and simulated snow series by the GRENBLS model: (A) inter-annual evolution of snow pack, (B) maximum snow water equivalent (MSWE), (C) date when MSWE occurs (DMSWE; day of the hydrologic year, Day 1 = Sept 1 ) and (D) duration of the snowpack over the ground (DSP). MAE: Mean absolute error, MBE: mean bias error. Box plots: the solid and dotted lines within each box are the average and median of the annual values, respectively; the lower and upper extremes of each box indicates the 25 and 75 percentiles, respectively; the lower and upper bars indicate 10 and 90 percentiles, respectively

\subsection{Accuracy of GRENBLS model in simulating snowpack evolution}

Fig. 3A shows a good match between the GRENBLSsimulated snow depth evolution using climatic records and the observed snow depth at the same site. Annual correlation coefficients are always $>0.75$ and usually (8 of $10 \mathrm{yr}$ ) >0.9. Despite some minor disagreements, GRENBLS generally reproduces essential features, such as the high inter-annual variability as well as the main patterns in the annual cycle of the snowpack. Fig. $3 \mathrm{~B}$ to D shows the annual values for 3 parameters considered representative of snow evolution. Simulated snowpack shows only an average absolute bias (MAE) of $25 \mathrm{~cm}$ in depth when maximum accumulation occurs, and the error is very close to zero when the sign of the bias is included in the average (MBE). The date of occurrence of simulated maximum accumulation is very close to that for observations (a mean difference of $11 \mathrm{~d}$ ); a similar accuracy was obtained for simulation of the duration of snow cover. Box plots show that the simulated series accurately reproduced the observed inter-annual variability of the 3 parameters, as indi- cated by the similar ranges in observed and simulated distributions. Correlation coefficients between annual snow parameters are always $>0.79$. The agreement index (Willmott's $D$; Willmott 1981) shows values $>0.81$ in all cases (Willmott's $D$ varies from 0 to 1,1 is a perfect prediction). This indicates a high agreement between measured and simulated snowpack. Thus, despite a few shortcomings in the reproduction of snowpack, it is considered that overall the simulation reproduced the observed snow realistically.

\subsection{Sensitivity of SEB to changes in climatic drivers}

Following assessment of the reliability of the snow series simulated by GRENBLS, the sensitivity of snowpack to changing climatic conditions was assessed by varying 1 by 1 the drivers in successive simulations. Fig. 4 shows the results obtained for the year 2002-2003, and Fig. 5 shows the annual snow parameters obtained when each of the climatic drivers was varied compared to those simulated with the observed values. 

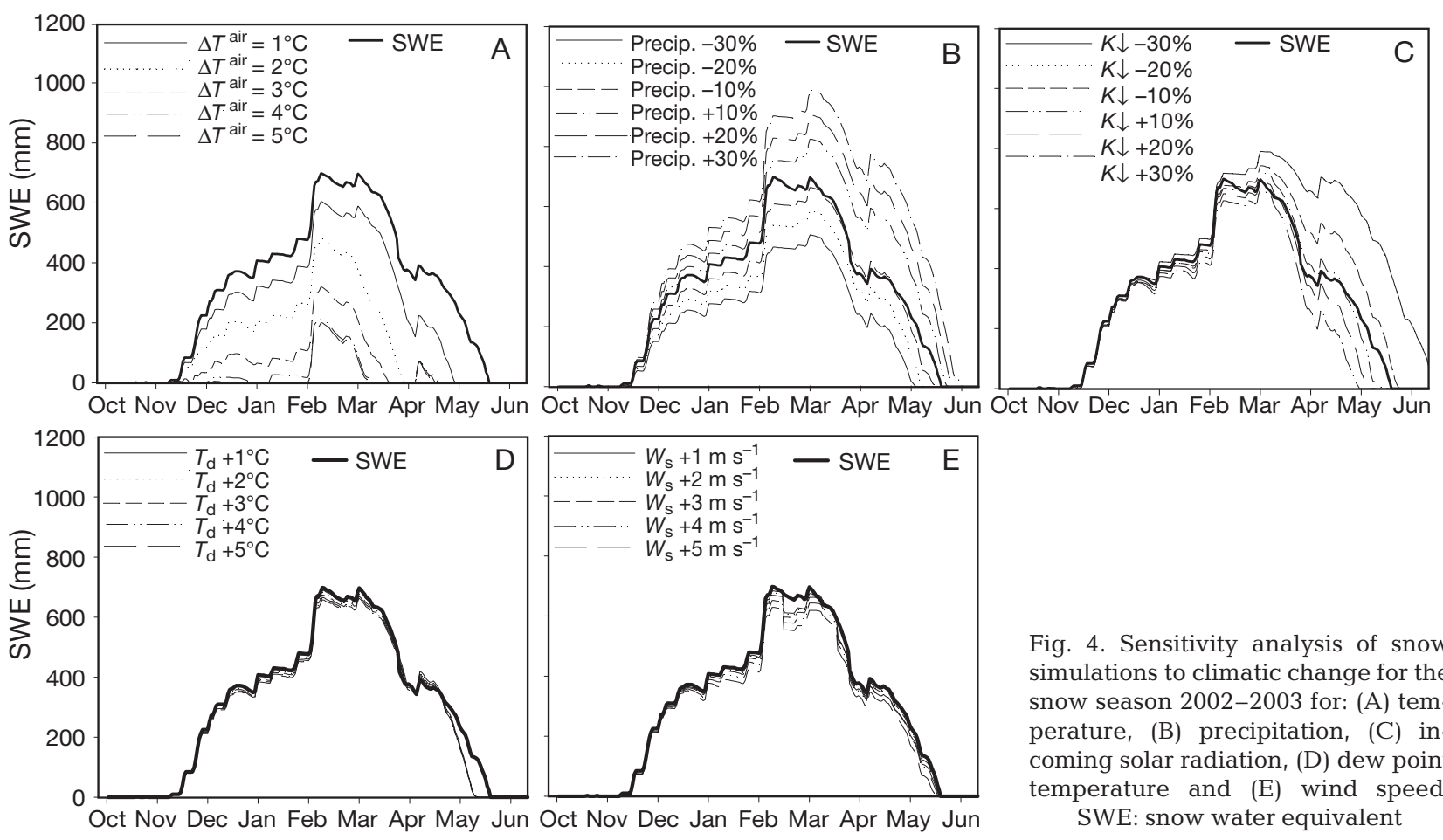

Fig. 4. Sensitivity analysis of snow simulations to climatic change for the snow season 2002-2003 for: (A) temperature, (B) precipitation, (C) incoming solar radiation, (D) dew point temperature and (E) wind speed. SWE: snow water equivalent

Fig. 4A shows the large sensitivity of SWE when simulated with increasing temperatures. Each degree of warming produced a marked decrease in MSWE, especially for the first 4 degrees where a mean reduction of $70 \mathrm{~mm}^{\circ} \mathrm{C}^{-1}$ (16\% of the mean MSWE) occurred. Over the subsequent $5^{\circ} \mathrm{C}$ increase, a lower sensitivity was observed, as MSWE only decreased by $20 \mathrm{~mm}$ on average. Moreover, DMSWE was noticeably brought forward and the duration of snowpack was shortened by an average of $20 \mathrm{~d}^{\circ} \mathrm{C}^{-1}$ (11\% of the mean DSP).

Snowpack was also very sensitive to changes in precipitation (Figs. 4B \& 5B). The most affected snow parameter was MSWE, with a mean change of $54 \mathrm{~mm} \mathrm{(13 \% )}$ for every $10 \%$ of change in precipitation. The duration of snowpack was also noticeably affected by changes in precipitation, but less so than by temperature, with a mean difference close to a month between the 2 most extreme simulations $(-30$ to $+30 \%)$. As expected, DMSWE was largely unaffected by precipitation changes.

Snow evolution showed a marked sensitivity to changes in incoming solar radiation. Fig. 5C shows that the 3 snow parameters were noticeably affected, in particular the maximum accumulation and the duration of snowpack (an average decrease of $29 \mathrm{~mm}$ and $11 \mathrm{~d}$, respectively, with a $10 \%$ increase in radiation).

Snowpack was also sensitive to changes in $T_{\mathrm{d}}$ and $W_{\mathrm{s}}$ (Figs. 4D, 5D and 4E, 5E, respectively), but the response was much weaker than that observed for $T, P$, or $K \downarrow$. Snowpack behaved practically insensitive to changes in cloud cover and atmospheric surface pressure (results are not shown).

\subsection{Response of snowpack to projected climate change at the study site}

Fig. 6A,B shows the snow evolution simulated using the observed climatic drivers and the modified climatic series according to different RCM projections, assuming a change in temperature only (left), temperature and precipitation (centre), and in all the climatic drivers (right) for the years 2002-2003 (high snow accumulation) and 2005-2006 (low snow accumulation), respectively. Fig. 6C shows the mean inter-annual probability magnitude curves (November to May) of the simulated series for the observed and modified series, and indicates that according to the expected climatic change in the area, a substantial decrease in snow accumulation can be expected. Warmer temperatures appear to be the main cause of decreasing snow depth throughout the full snow season. Indeed, the simulated series, which included shifts in precipitation (centred plots) and the change in all the climatic drivers $\left(T, P, T_{\mathrm{d}}, p_{\mathrm{sfc}}, K \downarrow, W_{\mathrm{s}}\right)$, were practically identical to those carried out assuming a change only in temperature. This result is a consequence of the expected stable behaviour of $P$ and $K \downarrow$ in the area for the coming decades (see Section 4.1), and these 2 variables together with temperature cause a significant response in the snow pack, as shown in the sensitivity analysis (Section 4.3). Figures indicate that in future years characterized by a thick snowpack, as represented by the modified series corresponding to the 2002-2003 season, accumulation will be less than half of observed 

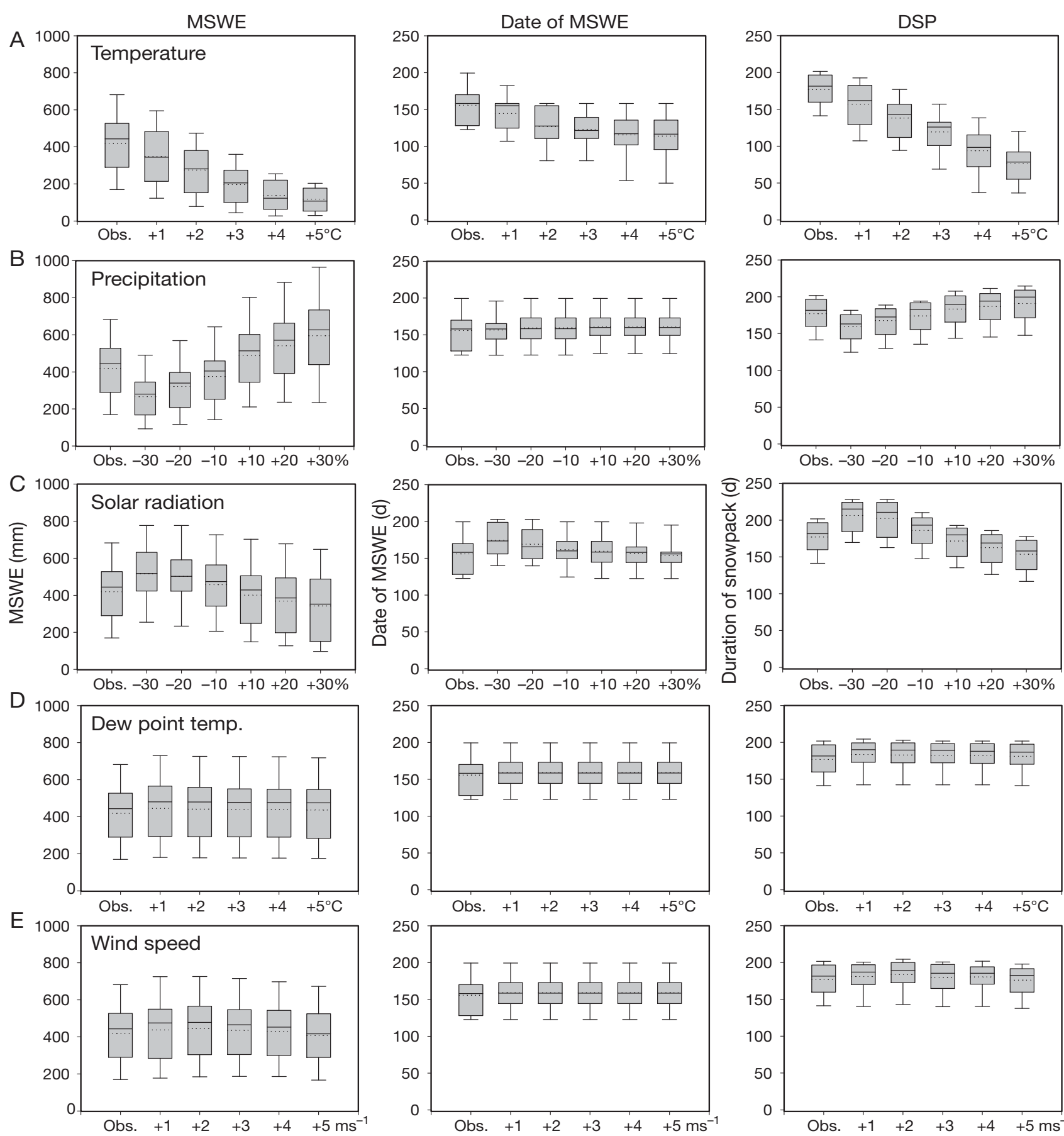

Fig. 5. Annual snow parameters obtained in the sensitivity analysis of snowpack to climatic change: (A) temperature, (B) precipitation, (C) incoming solar radiation, (D) dew point temperature and (E) wind speed. For explanation of box plots, see Fig. 3. MSWE: maximum snow water equivalent, DSP: duration of snowpack

current values and will be similar to the accumulation observed in 2005-2006, a year characterized by low accumulation. Under future climate conditions, snowpack during years with the most adverse conditions for accumulation (i.e. perturbed 2005-2006) will be negligible in terms of accumulation and duration, as evidenced by simulations shown in Fig. 6B. The probabil- ity magnitude curves shown in Fig. 6C indicate that climate change will exert strong shifts in the full distribution of frequencies of the snow series.

Fig. 7 shows the annual snow parameters, extracted from the simulated series for observed climate, with modified climatic drivers $\left(T, P, p_{\mathrm{sfc}}, T_{\mathrm{d}}, W_{\mathrm{s}}\right.$ and $\left.K \downarrow\right)$. Mean changes for the 1996 to 2006 period are provided 


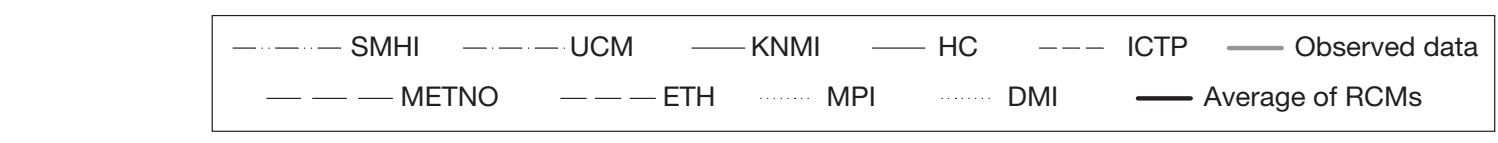

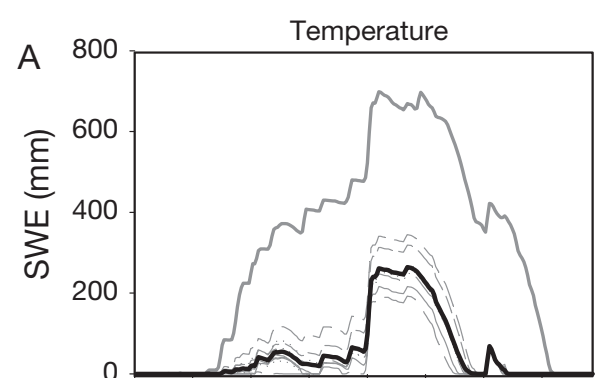

Temperature and precipitation
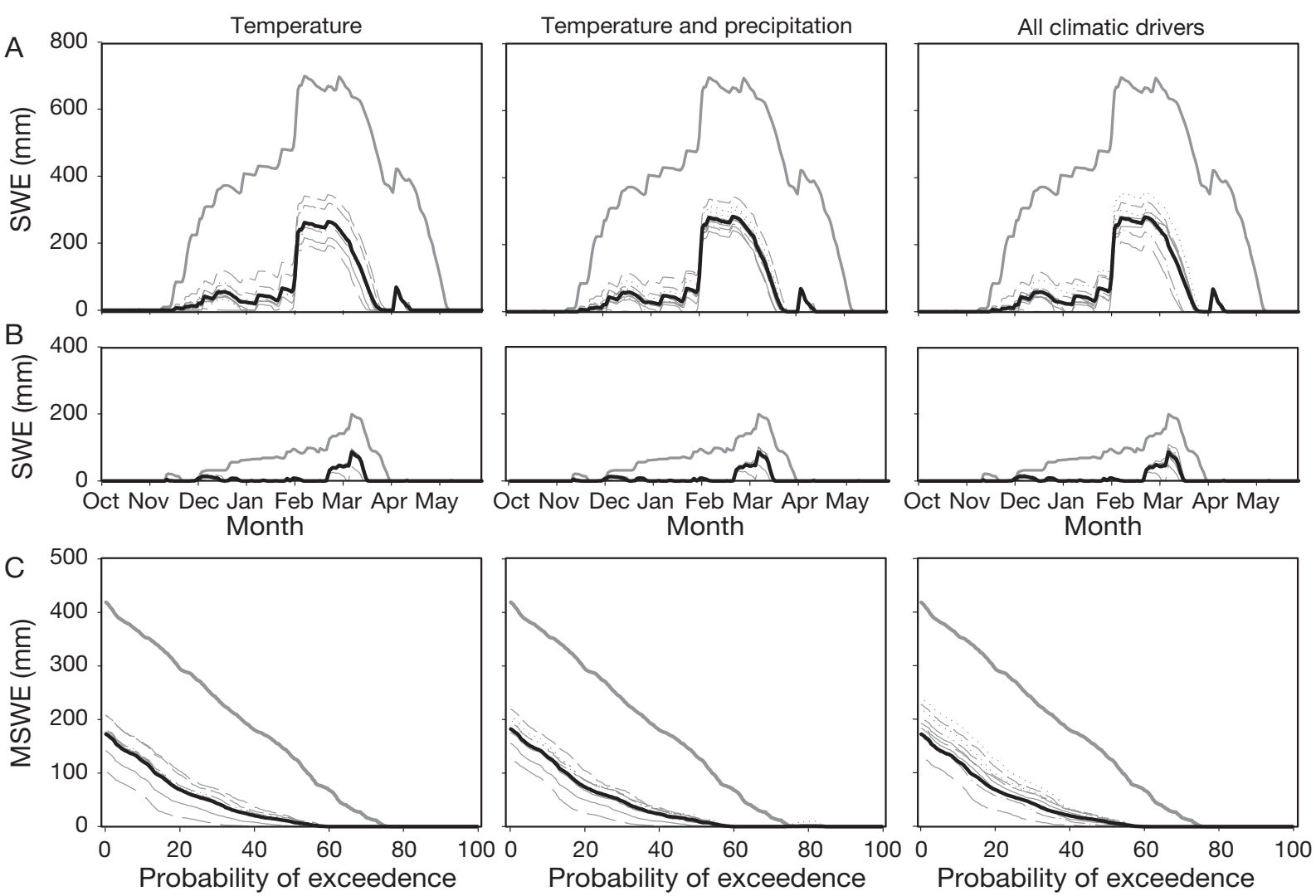

Fig. 6. Snow evolution series simulated from observed climate, and modified climatology according to RCM projections. Assumed climatic change includes: temperature only (left panels), temperature and precipitation (middle panels) and all climatic drivers (right panels): (A) snow season 2002-2003, (B) snow season from 2005-2006 and (C) inter-annual average probability magnitude curves (November to May period). SWE: snow water equivalent, MSWE: maximum SWE. For definitions of RCMs, see Section 3.3

in Table 2, assuming shifts in temperature, precipitation and temperature, and all climatic drivers. The results confirm that snow processes in the Pyrenees will be subject to dramatic shifts if RCM projections are accurate. Thus, MSWE is expected to decline an average of 50.3 to $58.7 \%$. Under a greenhouse climate, maximum snow accumulation during the most snowabundant years will be on the order of 25 to $50 \%$ of present conditions. As shown in Fig. 6B, in future, lowsnowfall years (bottom 10\%), accumulation will be $<50 \mathrm{~mm}$, in contrast to the $200 \mathrm{~mm}$ reached as a minimum in the 1996 to 2006 series. Maximum accumulation will occur at least 1 mo earlier (Fig. 7B), shifting from mid-March to mid-February. DSP (Fig. 7C) will be reduced by $>2$ mo on average. During the observation period snow persisted for at least $141 \mathrm{~d}$, but projections for future years suggest that a thin snowpack will only persist for 18 to $50 \mathrm{~d}$, depending on the model used.
In spite of differences in the magnitude, and in some cases sign, of projected changes in the climatic drivers of the SEB (see Section 4.1), there is a large degree of coherence amongst the different climatic change models with respect to projections for future snowpack. This is evident in the similar averages and ranges predicted by the different RCMs for parameters at the end of the 21st century (Fig. 7).

In addition to the large changes predicted for snowpack magnitude and duration in the future, coefficients of variation $\left(\mathrm{CV}_{\text {; }}\right.$ mean divided by the standard deviation) for the annual snow parameters point to a marked increase in inter-annual variability of snow processes in the region. Thus, annual MSWE values had a CV of 0.38 for the 1996 to 2006 period, whereas the CV of MSWE from the simulated series oscillates between 0.49 and 0.58 for the end of the 21st century, depending on the RCM used. Similarly, the CV for DMSWE shifts from 0.16 to $0.19-0.31$, and for DSP shifts from 0.13 to $0.31-0.43$. 

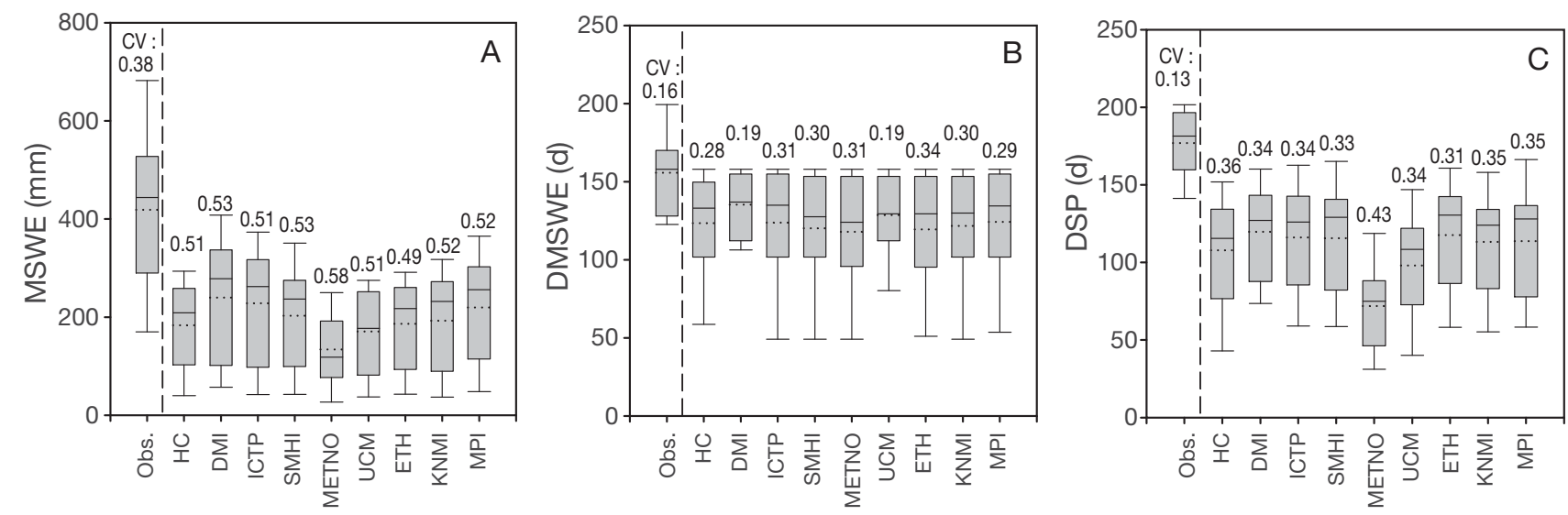

Fig. 7. Annual snow parameters obtained from simulated series with observed climate, and with modified climatology (all climatic drivers) according to RCM projections: (A) maximum snow water equivalent (MSWE), (B) date of MSWE (DMSWE) and (C) duration of snowpack (DSP). Numbers above box plots are the coefficients of variation (CV). For definitions of RCMs, see Section 3.3

\section{DISCUSSION AND CONCLUSIONS}

Simulation of the SEB under observed and modified climatic conditions enabled detection of the main variables that affect the temporal evolution of a snowpack in the Pyrenees, as well as quantification of changes in snow processes expected under future climate scenarios in the area (2070 to 2100 ; IPCC Scenario A2) projected by 9 RCMs. The methodology used should be applicable to other mountain areas with a reasonably long and complete record of variables that control SEB. The main findings are:

1. Snowpack is highly sensitive to potential changes in temperature, precipitation and solar radiation; response is less sensitive to shifts in air dew point temperature and wind speed.

2. RCMs predict a sharp increase in temperature $(2.5$ to $3.6^{\circ} \mathrm{C}$ ) by the end of the 21 st century, a moderate increase in air humidity, and nearly stable conditions for the rest of the driving variables of SEB.

3. Simulations based on future climatic conditions projected by 9 different RCMs produced consistent results, all pointing to changes similar in sign and magnitude.

4. The main changes in snow processes detected in this study using a warming scenario were a marked decrease of MSWE (50 to $59 \%$ ), an earlier occurrence of DMSWE (32 to $35 \mathrm{~d}$ ), and a reduction in snow cover of 67 to $74 \mathrm{~d}$. In addition, there was a noticeable increase in inter-annual variability in snow processes.

For an appropriate interpretation of the results from the sensitivity analysis, it is of paramount importance to take into account that variations of individual meteorological parameters alone are not responsible for variations in energy fluxes because of the non-linear relations linking them to the heat. In spite of this consideration, results seem robust in indicating temper- ature, precipitation and solar radiation as major factors in snow accumulation and melting processes (e.g. Keller et al. 2005, Pohl et al. 2006). In the present study, temperature was the parameter with the greatest effect on snowpack, which is in agreement with the results obtained in other mountain ranges, including the Alps and the Himalayas. For example, Singh \& Bengtsson (2003) showed accelerated depletion of the snow-covered area in the north of India $\left(20,31\right.$ and $40 \mathrm{~d}$ for $T^{\circ} \mathrm{C}+$ $1, T^{\circ} \mathrm{C}+2$ and $T^{\circ} \mathrm{C}+3$ scenarios, respectively). In the Austrian Alps, Hantel \& Hirtl-Wielke et al. (2007) showed a 4 to 6 wk shortening of the snow season with a warming of $1^{\circ} \mathrm{C}$. Rasmus et al. (2004) linked the projected warmer climate to a decrease in snow-cover thickness and duration. In addition, they expected notable changes in snow quality: denser and closer to the melting point even in winter, larger grain sizes, a smaller fraction of depth hoar in the snowpack and a larger fraction of icy or wet snow in the snow cover. The magnitude of listed changes will be largely subjected to the location of the meteorological observatories used for the analysis. Similarly, Beniston et al. $(2003 a, b)$ showed large reductions in snow volume with increased temperature in the Swiss Alps, but the effect had a strong vertical gradient, with the changes being

Table 2. Expected mean changes in snow parameters according to regional climate model projections. MSWE: maximum snow water equivalent, DMSWE: date of MSWE, DSP: duration of snowpack

\begin{tabular}{|lcccccc|}
\hline Change & \multicolumn{2}{c}{ MSWE } & \multicolumn{2}{c|}{ DMSWE } & \multicolumn{2}{c|}{ DSP } \\
& $(\mathrm{mm})$ & $(\%)$ & $(\mathrm{d})$ & $(\%)$ & $(\mathrm{d})$ & $(\%)$ \\
\hline $\begin{array}{l}\text { Temperature } \\
\begin{array}{c}\text { Temperature and } \\
\text { precipitation }\end{array}\end{array}$ & -245 & -58.7 & -34 & -21.8 & -74 & -41.8 \\
$\begin{array}{l}\text { All variables } \\
\text { vara. }\end{array}$ & -225 & -53.8 & -32 & -22.6 & -64 & -36.6 \\
\hline
\end{tabular}



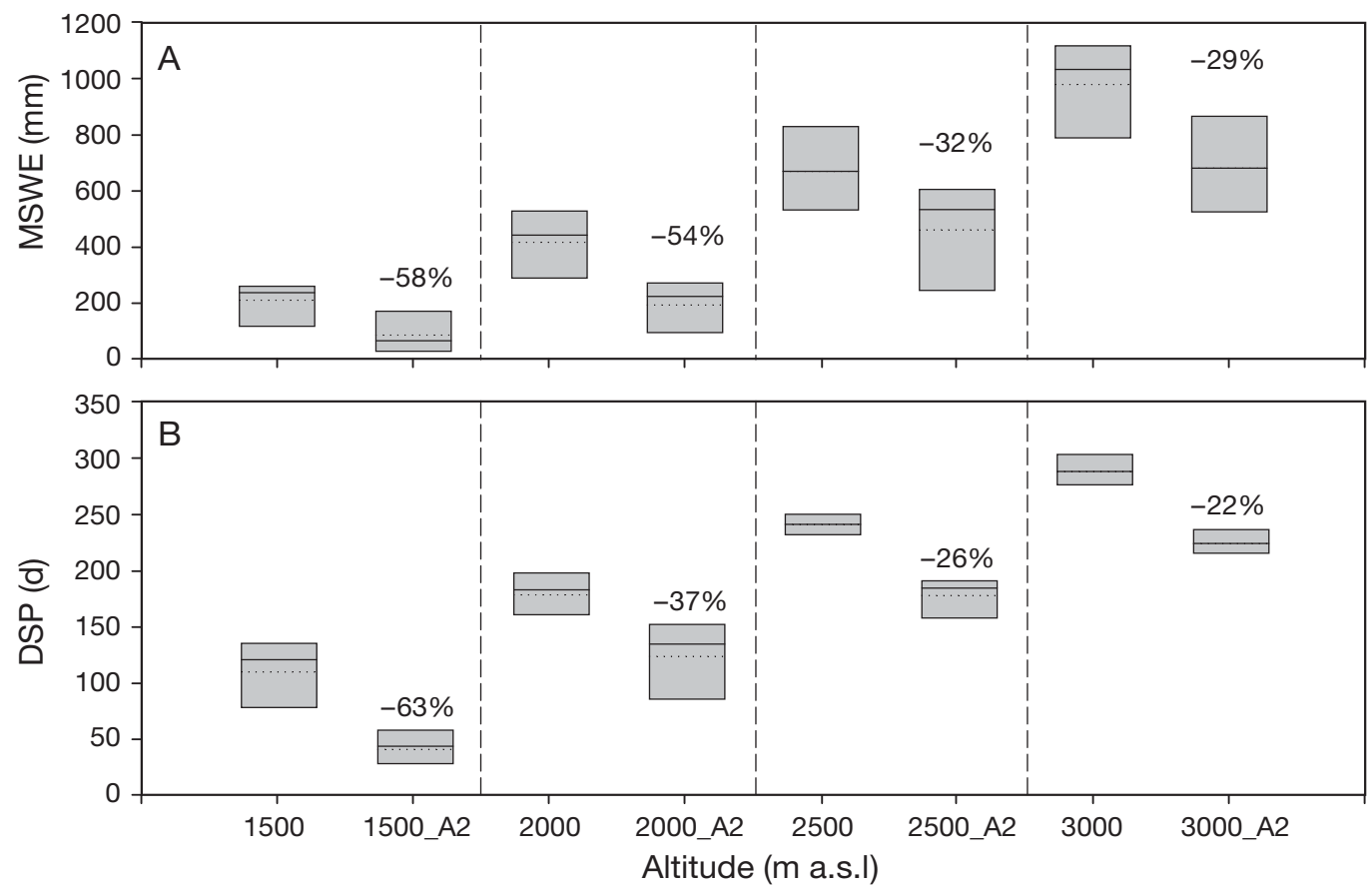

Fig. 8. Estimated mean shifts in: (A) snowpack accumulation (maximum snow water equivalent, MSWE) and (B) duration of the snowpack (DSP) under modified climate at 1500, 2000, 2500 and $3000 \mathrm{~m}$ a.s.l. assuming a temperature lapse rate of $0.65^{\circ} \mathrm{C}$ $100 \mathrm{~m}^{-1}$ between current climate conditions and those simulated by the end of the 21st century (A2). Percentages indicate the change with respect to current conditions

more intense at lower altitudes where $T$ is close to $0^{\circ} \mathrm{C}$. Similarly, for the Pyrenees, Fig. 8 shows simulations of snowpack under current and future conditions at 1500, 2000, 2500 and $3000 \mathrm{~m}$ a.s.l. (assuming a temperature lapse rate of $0.65^{\circ} \mathrm{C} 100 \mathrm{~m}^{-1}$, and neglecting potential vertical gradients in precipitation). They also reveal a larger impact of the climate change for different altitudinal bands. The magnitude of shifts indicates a marked non-linear relationship between altitude and snowpack, with the largest changes below 2000 m a.s.l. For this reason, results shown here are directly applicable to the sub-alpine areas of the Pyrenees as well as the belt where the Izas Station is located. Further research will be required to determine in detail the spatial and vertical variability of the climate change impacts on snowpack. However, this task will require new assumptions to downscale the data and to disaggregate into hourly data the daily outputs provided by RCMs.

Modelling has indicated that changes in precipitation have less effect than variations in temperature, but can significantly modify the evolution of snowpack (Lapp et al. 2005, Singh et al. 2006). The weak influence of atmospheric humidity on snowpack found in this study agrees with the findings of a sensitivity analysis carried out in the southern Canadian Rockies (Lapp et al. 2005). The same study showed a greater influence of wind speed on sublimation and, hence, on total snow volume than that found in our analysis.
The maintenance of stable precipitation and radiation over the next decades in the studied area led, in simulations, to a dominant effect of temperature on future changes in snowpack; the inclusion of precipitation or other climatic drivers as changing variables barely modified the predicted snow series for the end of the 21st century.

According to previous studies that analysed uncertainties in RCM outputs (Räisänen 2007 and references therein), similarities in the expected shifts under different climate models, as obtained here, indicate the robustness of the projections. These changes, even under lower greenhouse gas emission scenarios, indicate the magnitude of the consequences of climate change on natural processes and socio-economic activities related to snow. With respect to hydrology, the decrease in snow volume could lead to a marked shift in the seasonal distribution of river flows. Such a change has already become noticeable in the Pyrenees as a consequence of a negative trend in snow accumulation during the second half of the 20th century (López-Moreno \& García-Ruiz 2004). Expected changes for the mid-term future far exceed those observed in recent decades (López-Moreno 2005). Thus, increased winter flows but decreased spring flows are expected, requiring major changes in reservoir management strategies. The scenarios for snow accumulation and duration make the economic future uncertain for ski 
resorts in the Pyrenees, which have already experienced economic difficulties during seasons with little snow. Together with the reduced snow volume and duration of cover, the expected increase in interannual variability will enhance the year-to-year uncertainty of activities linked to snowpack.

Results shown in this study are subject to a number of uncertainties related primarily to the accuracy of the climatic series provided by the RCMs. Much effort has been devoted to quantifying the confidence that can be placed in the climatic change projections. Typically, this increases for an area where the models are able to reproduce the observed climate in comparisons of control runs with observational records that cover the same period (1960 to 1990 in this case), and where the changes predicted by most of the RCMs coincide in sign and magnitude (Giorgi et al. 2004, Dequé et al. 2005, Räisänen 2007). A previous study in the Pyrenees (López-Moreno et al. 2008) concluded that the observed temperature during the control period was well reproduced by the RCMs, with biases around $1^{\circ} \mathrm{C}$ and a high degree of agreement amongst the compared models. However, biases in simulated precipitation compared to observed precipitation were up to $25 \%$, and the heterogeneity amongst the different RCMs was rather high. In this study, expected changes in precipitation projected by the RCMs for the study site also showed marked differences in magnitude and, in some cases, sign. In addition to uncertainty regarding the magnitude of future change, precipitation in the Pyrenees is likely to be subject to large spatial variability, with an increase expected in the west and a decrease in the east. This pattern contrasts with the relatively homogeneous spatial distribution of change expected for temperature (López-Moreno et al. 2008). The variability in precipitation trends makes application of the results obtained at the Izas Station to the rest of the mountain range unreliable. However, when snowpack is simulated with the expected changes in temperature (considered quite robust), but assuming a $30 \%$ increase in precipitation (an extremely optimistic projection for the Pyrenees), the main changes in snow processes described above were maintained. Thus, Fig. 9 shows that, although the changes in snow processes were moderate, large shifts were still predicted, including an average decrease in MSWE of $37 \%$, a DSWE occurring $32 \mathrm{~d}$ earlier, and a reduction of $54 \mathrm{~d}$ in the DSP. This highlights the exposure to expected cli-
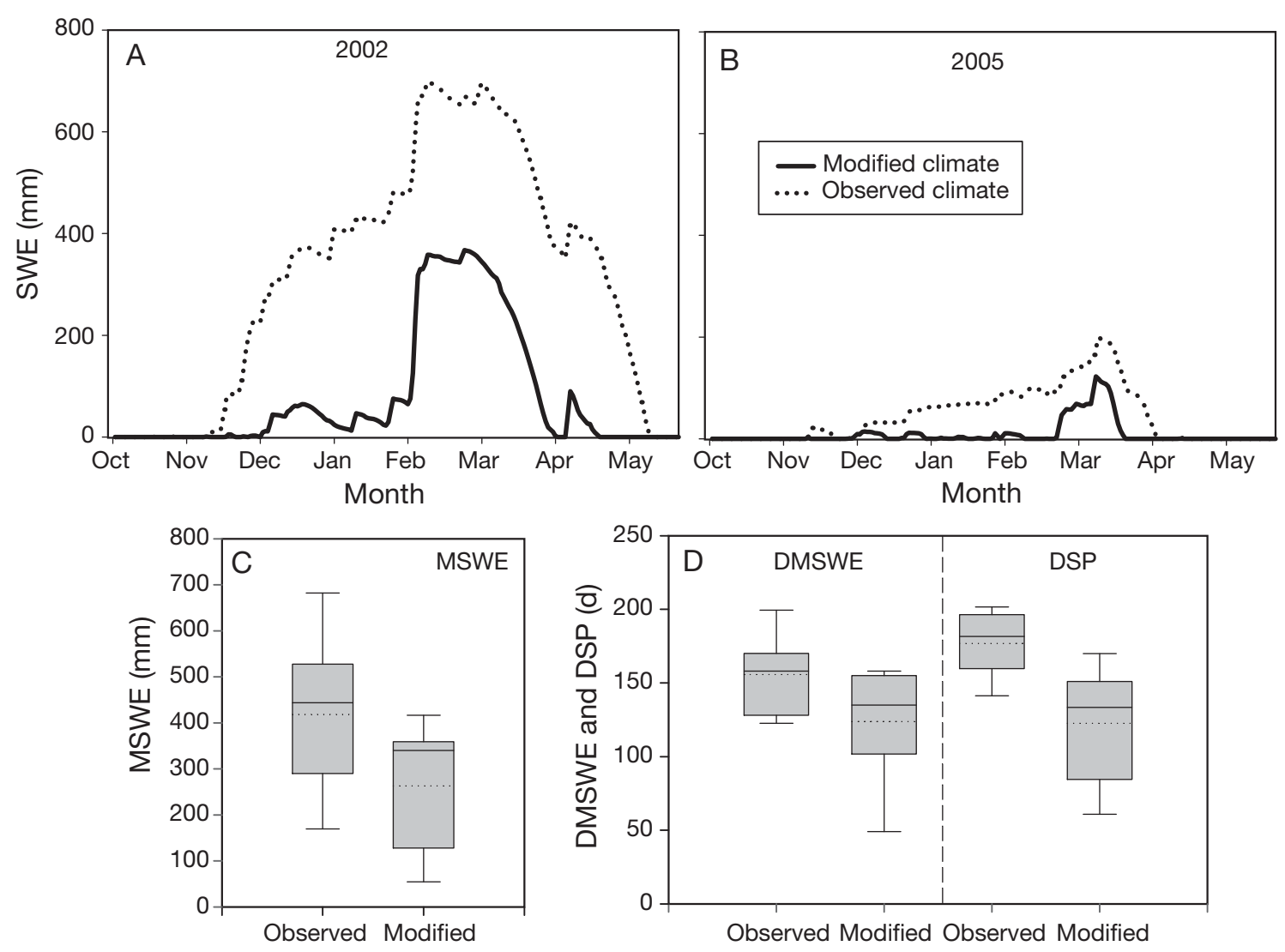

Fig. 9. Mean shifts in snowpack assuming the change in temperature projected by RCMs and an increase in precipitation of $30 \%$ : (A) snow season 2002-2003, (B) snow season 2005-2006 (snow water equivalent, SWE), (C) maximum SWE (MSWE) and (D) date of MSWE (DMSWE) and duration of snowpack (DSP) 
mate change of ecological processes and economic activities that depend on snow in the Pyrenees, even under more optimistic emission scenarios.

Finally, one goal would be to simulate the spatial variability of snow cover melting on the runoff generation at a catchment scale. The distributed energy balance of snowmelt coupled with hydrologic modelling is thus required (e.g. Kirnbauer et al. 1994, Marks et al. 1999, Garen \& Marks 2005). Such an approach has an advantage of resolving topographical features of the snow cover at a resolution not yet resolved by highresolution RCMs. On the other hand, the validation is hampered by the lack of a continuous and dense network of observations to drive and to validate this modelling system. Consequently, for the time being, reliance is on hybrid approaches using available observations, model outputs, as well on a number of assumptions to drive the energy balance model with respect to specific points.

Acknowledgements. This study has been supported by the following projects: PROBASE CGL2006-11619, CANOA CGL 2004-04919-c02-01, both financed by the Spanish Commission of Science and Technology and FEDER. Maintenance of the Izas Experimental Catchment is funded by LUCDEMERESEL-DGCONA, Spanish Ministry of Environment. The authors thank the PRUDENCE project for open access to climate model output, and those people who collaborated in the installation and maintenance of the Izas Experimental Station. J.I.L.M. was supported by postdoctoral fellowships from the Spanish Ministry of Education, Culture and Sports.

\section{LITERATURE CITED}

Anderson EA (1973) National Weather Service river forecast system - snow accumulation and ablation model. NOAA Tech Mem 17:1-217

Anderson EA (1976) A point energy balance model of a snow cover. NOAA Tech Rep 19:1-150

Anderton SP, White SM, Alvera B (2004) Evaluation of spatial variability in snow water equivalent for a high mountain catchment. Hydrol Process 18:435-453

Beniston M (1997) Variations of snow depth and duration in the Swiss Alps over the last 50 years: links to changes in large-scale climatic forcing. Clim Change 36:281-300

Beniston M (2006) August 2005 intense rainfall event in Switzerland: not necessarily an analog for strong convective events in a greenhouse climate. Geophys Res Lett 33: L05701

Beniston M, Keller F, Goyette S (2003a) Snow pack in the Swiss Alps under changing climatic conditions: an empirical approach for climate impacts studies. Theor Appl Climatol 74:19-31

Beniston M, Keller F, Koffi B, Goyette S (2003b) Estimates of snow accumulation and volume in the Swiss Alps under changing climatic conditions. Theor Appl Climatol 76: $125-140$

Benoit R (1977) On the integral of the surface layer profilegradient functions. J Appl Meteorol 16:859-860

Brown R, Bartlett P, Mackay M, Verseghy D (2006) Evaluation of snow cover in CLASS for SnowMIP. Atmos-Ocean 44:223-238

Brun E, Martin E, Simon V, Gendre C, Coleou C (1989) An energy and mass balance model of snow cover suitable for operational avalanche forecasting. J Glaciol 35:333-342

Christensen JH, Christensen OB (2003) Severe summertime flooding in Europe. Nature 421:805-806

Christensen OB, Christensen JH (2004) Intensification of extreme European summer precipitation in a warmer climate. Global Planet Change 44:107-117

Dankers R, Christensen OB (2005) Climate change impact on snow coverage, evapotranspiration and river discharge in the subarctic Tana basin, northern Fennoscandinavia. Clim Change 69:367-392

Del Barrio G, Alvera B, Puigdefábregas J, Díez C (1997) Response of high mountain landscape to topographic variables: Central Pyrenees. Landscape Ecol 12:95-115

Dequé M, Jones RG, Wild M, Giorgi F and others (2005) Global high resolution versus limited area model climate change projections over Europe: quantifying confidence level from PRUDENCE results. Clim Dyn 25:653-670

Etchevers P, Martin E, Brown R, Fierz C and others (2004) Validation of the energy budget of an alpine snowpack simulated by several snow models (SnowMIP project). Ann Glaciol 38:150-158

García-Ruiz JM, Puigdefábregas J, Creus J (1986) La acumulación de la nieve en el Pirineo Central y su influencia hidrológica. Pirineos 127:27-72

> Garen DC, Marks D (2005) Spatially distributed energy balance snowmelt modelling in a mountainous river basin: estimation of meteorological inputs and verification of model results. J Hydrol 315:126-153

Giorgi F, Bi X, Pal JS (2004) Mean interannual variability and trends in a regional climate change experiment over Europe. I. Present-day climate (1961-1990). Clim Dyn 22:733-756

Hantel M, Hirtl-Wielke LM (2007) Sensitivity of alpine snow cover to European temperature. Int $\mathrm{J}$ Climatol 27: 1265-1275

Kalnay E, Kanamitsu M, Kistler R, Collins W and others (1996) The NCEP/NCAR 40-years reanalysis project. Bull Am Meteorol Soc 77:437-471

> Keller F, Goyette S (2005) Snowmelt under different temperature increase scenarios in the Swiss Alps. In: Dejong C, Collins DN, Ranzi R (eds) Climate and hydrology of mountain areas. Wiley, New York

Keller F, Goyette S, Beniston M (2005) Sensitivity analysis of snow cover to climate change scenarios and their impact on plant habitats in alpine terrain. Clim Change 72 : 299-319

Kirnbauer R, Blöschl G, Gutknecht D (1994) Entering the era of distributed snow models. Nord Hydrol 25:1-24

Lapp S, Byrne J, Townshend I, Kienzle S (2005) Climate warming impacts on snowpack accumulation in an alpine watershed. Int J Climatol 25:521-536

Laprise R, Caya D, Giguère M, Bergeron G and others (1998) Climate and climate change in western Canada as simulated by the Canadian regional climate model. AtmosOcean 36:119-167

López-Moreno JI (2005) Recent variations of snowpack depth in the central Spanish Pyrenees. Arct Antarct Alp Res 37:253-260

> López-Moreno JI, García-Ruiz JM (2004) Influence of snow accumulation and snowmelt processes on the distribution of streamflow in the central Spanish Pyrenees. J Hydrol Sci 49:787-802

López-Moreno JI, Nogués-Bravo D (2005) A generalized 
additive model for the spatial distribution of snowpack in the Spanish Pyrenees. Hydrol Process 19:3167-3176

López-Moreno JI, Vicente-Serrano SM (2007) Mapping of snowpack distribution over large areas using GIS and interpolation techniques. Clim Res 33:257-270

López-Moreno JI, Goyette S, Beniston M (2008) Climate change prediction over complex areas: spatial variability of uncertainties and expected changes over the Pyrenees from a set of regional climate models. Int J Climatol (in press) doi: 10.1002/joc.1645

Marks D, Domingo J, Susong D, Link T, Garen D (1999) A spatially distributed energy balance snowmelt model for application in mountain basins. Hydrol Process 13: 1935-1959

McFarlane NA, Boer GJ, Blanchet JP, Lazare M (1992) The Canadian climate centre second generation general circulation model and its equilibrium climate. J Clim 5: 1013-1044

Mellander PE, Laudon H, Bishop K (2005) Modelling variability of snow depths and soil temperatures in Scots pine stands. Agric For Meteorol 133:109-118

Mellander PE, Löfvenius MO, Laudon H (2007) Climate change impact on snow and soil temperature in boreal Scot pine stands. Clim Change 85:179-193

Merritt W, Alila Y, Barton M, Taylor B, Cohen S, Neilsen D (2006) Hydrologic response to scenarios of climate change in sub watersheds of the Okanagan basin, British Columbia. J Hydrol 326:79-108

Nakicenovic N, Grübler A, McDonalds A (1998) Global energy perspectives. Cambridge University Press

Outcalt SI, Goodwin C, Weller G, Brown J (1975) A digital

Editorial responsibility: Daniel Scott,

Waterloo, Ontario, Canada computer simulation of the annual snow and soil thermal regimes at Barrow, Alaska. Research Report 331, Cold Regions Research and Engineering Laboratory, Hanover, $\mathrm{NH}$

Paltridge G, Platt C (1976) Radiative processes in meteorology and climatology. Developments in Atmospheric Science, No. 5. Elsevier, Amsterdam

Pohl S, Marsh P, Pietroniro A (2006) Spatial-temporal variability in solar radiation during spring snowmelt. Nord Hydrol 37:1-19

Räisänen J (2007) How reliable are climate models? Tellus 59:2-29

> Rasmus S, Räisänen J, Lehning M (2004) Estimating snow conditions in Finland in the late 21st century using the SNOWPACK model with regional climate scenario data as input. Ann Glaciol 38:238-244

Rockel B, Raschke E, Weyres B (1991) A parameterization of broad band radiative transfer properties of water, ice and mixed clouds. Beitr Phys Atmos 64:1-12

Singh P, Bengtsson L (2003) Effect of warmer climate on depletion of snow covered area in the Satluj basin in western Himalayan region. Int J Hydrol Sci 48:413-425

Singh P, Arora M, Goel NK (2006) Effect of climate change on runoff of a glaciarized Himalayan basin. Hydrol Process 20:1979-1992

Stull RB (1988) An introduction to boundary layer meteorology. Kluwer Academic Publishers, Dordrecht

Thodsen H (2007) The influence of climate change on stream flow in Danish rivers. J Hydrol 333:226-238

Willmott CJ (1981) On the validation of models. Phys Geogr 2: $184-194$

Submitted: November 2, 2007; Accepted: April 1, 2008

Proofs received from author(s): May 20, 2008 